further research. Here visits were paid to groups belonging to Guaporé culture, but not classified linguistically. A prolonged stay in a village halfway between Presidente Hermes and Presidente Penna, of which the inhabitants were numerically poor and culturally degenerate, nevertheless proved fruitful in sociological material. Towards the end of the year, on reaching Presidente Penna, the return of the expedition by the normal route towards the south was barred by torrential rains and the illhealth of the members of the expedition. It was, therefore, decided to leave the country by the north in the direction of the Rio Madeira and then west to Bolivia.

\section{Research on Lawns}

INVESTIGATION of the particular ecological problems which relate to lawns began in America towards the end of last century. It was not until 1920, however, that such research was prosecuted on a national scale in that country, and not until 1925 that any adequate provision was made in Great Britain. The report for 1938 of the Board of Greenkeeping Research, St. Ives Research Station, Bingley, Yorks. (pp. 1-77, price 2s., July 1939) shows to what adequate development the investigation of greenkeeping matters has now attained. There are ap. proximately 1,600 experimental plots at the Station, to inquire into the response of grass varieties to manurial and mechanical treatments, to control pests and diseases, and to select the most suitable varieties of grass for various purposes. Seed of the new strain of St. Ives Creeping Red Fescue is grown and distributed, whilst an improved strain of Agrostis tenuis should yield upon a small commercial scale in 1939. Experiments on the control of pearlwort and other weeds are in progress, the effects of sulphur as a dressing for heavy ground are being investigated, treatment of the soil with potassium permanganate for the control of earthworms has proved satisfactory, and various diseases of turf have also been studied. The Station now maintains an extensive permanent collection of greenkeeping implements, and has 'museum' plots of grass and weed speciesfeatures which are of great value to students who attend the two courses of instruction which are held during the year. Letters and advisory visits have reached higher maxima than in any previous year, and the results of the Station's researches are published in its Jonurnal and in various reprint publications.

\section{The Electric Battery Vehicle}

According to the Electrical Times of September 28 , one result of the outbreak of war is a considerable increase in the number of inquiries received by manufacturers of electric accumulators and vehicles as to the price of their wares, the charges of electricity required by the vehicles and the distance traversed for a given charge on a smooth road. Petrol rationing has compelled owners of motor-vehicles to curtail seriously their usual transport facilities, and they are considering the relative advantages of petrol and electricity for transport. Since electric vehicles take their power from storage batteries they are designed as a rule to have only a moderate range of action, varying from about 25 to 45 miles per charge of the batteries. The distance depends on the number of stops that have to be made. If the number of stops are numerous and the average time of a stop long, the advantage lies greatly on the side of the electric vehicle, since it only takes power when it is running. Most retail deliveries are carried out on a 'customer convenience' basis and not on 'transport economy basis'. It has been estimated that the petrol ration for $\mathrm{C}$ licence holders is only sufficient for their vans and lorries to cover half the normal mileage. If they have been doing about 75 miles per day, then they would be able to substitute an electric vehicle and still be in the same position as at present. For any distance between 35 and 75 miles per day, an electric vehicle would bo an excellent substitute for a petrol one. The electric vehicle has other advantages. It has a long life; low maintenance and cheap running costs enable it, for many duties, to prove superior to alternative transport methods. In addition, it has the advantage of being exceptionally clean, free from fumes and simple to operate. A one-ton carrying capacity petrol van running 10,000 miles a year will use about 650 gallons of petrol, whereas the electric will use 4,000 units of electricity, or about 3 tons of coal. Owing to the grid, if at any time difficulties in transport should arise, then those power stations involving the minimum amount of coal transport could take over much of the load.

\section{Properties and Testing of Heat-Insulating Materials}

A general discussion on "The Properties and Testing of Heat-Insulating Materials", organized by the Joint Committee on Materials and their Testing, in conjunction with the Institution of Gas Engineers, will be held in London on November 23. Authorities from Great Britain, the United States, France, and Canada are to take part. Further particulars can be obtained from the Secretary, Joint Committee on Materials and their Testing, Institution of Mechanical Engineers, Storey's Gate, London, S.W.1.

\section{Chemical Society}

The Chemical Society will continue to function at Burlington House, London, unless circumstances render it impracticable to do so. It is the intention of the Council to publish the Journal of the Chemical Society each month as heretofore and to issue the "Annual Reports on the Progress of Chemistry, 1939" in the early spring of 1940. British Chemical and Physiological Abstracts "A", Pure Chemistry, will also continue to be published monthly. The Council has accepted with great regret as from September 30 the resignation of Prof. J. W. Cook from the office of honorary secretary, on his appointment to the regius chair of chemistry of the University of Glasgow. It has expressed its high appreciation of the eminent services Prof. Cook has rendered to the Society during his term of office. Prof. W. Wardlaw, professor of physical chemistry in Birkbeck College, London, has 